\title{
EFFECTS OF EXOGENOUS ADRENOCORTICOTROPIC HORMONE (ACTH) UPON PITUITARY ACTH CONCENTRATION AFTER PROLONGED CORTISONE TREATMENT AND STRESS *
}

\author{
By DONALD A. HOLUB, $\dagger$ JULIAN I. KITAY $\ddagger$ AND JOSEPH W. JAILER \\ (From the Departments of Medicine, Obstetrics and Gynecology, Columbia University College \\ of Physicians and Surgeons, and Presbyterian Hospital, New York, N. Y.)
}

(Submitted for publication June 10, 1958; accepted October 9, 1958)

Symptoms and metabolic abnormalities closely resembling those of hypoadrenalism have been reported following cessation of prolonged treatment with adrenal steroids (1-5). Sudden death following surgery has been reported in association with this syndrome and has been ascribed to failure of the hypothalamic-pituitary-adrenal system to respond to stress (6-9). Since prolonged administration of corticosteroids produces adrenal atrophy in both man and laboratory animals (7, $10,11)$, this failure has been attributed to adrenal insufficiency. Exogenous corticotropin (ACTH) will repair or maintain normal adrenal weight in the cortisone-treated animal (12). Consequently the addition of ACTH in various dosage schedules has been advocated for the purpose of maintaining or restoring normal adrenal responsiveness to stress $(5,13-16)$. The efficacy of such combined therapy is not firmly established.

In addition to producing adrenal atrophy, chronic treatment with steroids results in decreased pituitary ACTH content $(17,18)$. The failure of steroid-treated subjects to respond to stress may therefore reflect pituitary ACTH insufficiency rather than, or in addition to, adrenal insufficiency. ACTH administration, on the other hand, has been shown to increase pituitary ACTH content in the intact rat, despite stimulation of secretion of endogenous steroids (18). For this reason ACTH therapy has been studied in the cortisonetreated animal to determine whether such adjunctive therapy is capable of modifying the pituitary ACTH depletion which follows steroid administration, and whether it can enhance the pituitary response to stress.

\footnotetext{
* Supported by a grant from the National Institutes of Health (A-195).

+ Fellow of The National Foundation.

$\ddagger$ Commonwealth Fund Fellow in Medicine.
}

\section{METHODS}

All experiments were performed in male rats of the Sherman strain (100 to $140 \mathrm{Gm}$.), kept in a constant temperature room for at least one week prior to use. The diet consisted of Purina Laboratory Chow and water ad libitum. Three treatments were employed as follows: Physiological saline $(0.1 \mathrm{ml}$.) was injected subcutaneously once daily; 4 U.S.P. units of ACTH gel $(0.1 \mathrm{ml}$.) was injected subcutaneously once daily; 2.5 or $5 \mathrm{mg}$. of cortisone acetate (either 0.1 or $0.2 \mathrm{ml}$.) was injected subcutaneously once daily. When adrenalectomized rats were used they were injected immediately after operation and were given 1 per cent saline in the drinking water.

Four experiments were performed as follows:

Experiment 1. Intact rats were injected with $5 \mathrm{mg}$. of cortisone for 7 days. Groups of four animals each were sacrificed at 1, 2, 4, 7 and 10 days after the last injection. The pituitary glands of each group were pooled and extracted for ACTH. Intact rats injected with saline for 7 days and sacrificed 24 hours after the last injection served as a control group.

Experiment 2. Adrenalectomized rats were injected with either $5 \mathrm{mg}$. of cortisone or 4 U.S.P. units of ACTH plus $5 \mathrm{mg}$. of cortisone for 7 days. A control group received saline. The pituitary glands were extracted individually for ACTH 24 hours after the last injection.

Experiment 3. Intact rats were divided into five groups and treated according to the following 10 day schedule:

\begin{tabular}{cll}
\hline \hline Group & \multicolumn{1}{c}{$\begin{array}{c}\text { Treatment 1 } \\
\text { (seven days) }\end{array}$} & $\begin{array}{c}\text { Treatment 2 } \\
\text { (three days) }\end{array}$ \\
\hline 1 (control) & Uninjected & Uninjected \\
2 & Cortisone, $2.5 \mathrm{mg}$. & Saline \\
3 & Cortisone, $2.5 \mathrm{mg}$. plus & Saline \\
4 & ACTH, 4 U & \\
5 & $\begin{array}{c}\text { Cortisone, 2.5 mg. } \\
\text { Cortisone, 2.5 mg. plus } \\
\text { ACTH, 4 U }\end{array}$ & ACTH, 4 U \\
& ACTH, 4 U \\
\hline
\end{tabular}

Twenty-four hours after completion of the injection schedule the animals in each group were subdivided into unstressed and stressed subgroups. Four hours after a scalding stress (19), both the unstressed and stressed subgroups were sacrificed simultaneously. This interval was chosen on the basis of previous experiments in which normal rats were scalded and sacrificed 1, 2, 4, 8 and 
24 hours after stress; the maximal depletion of pituitary ACTH was observed to occur at 4 hours. The pituitary glands of each subgroup were pooled and extracted for ACTH.

Experiment 4. Intact rats were divided into two groups and treated according to the following 10 day schedule:

\begin{tabular}{ccc}
\hline \hline Group & \multicolumn{1}{c}{$\begin{array}{c}\text { Treatment 1 } \\
\text { (seven days) }\end{array}$} & $\begin{array}{c}\text { Treatment 2 } \\
\text { (three days) }\end{array}$ \\
\hline 1 (control) & $\begin{array}{l}\text { Cortisone, 2.5 mg. } \\
\text { Cortisone, 2.5 mg. plus } \\
\text { ACTH, 4 U }\end{array}$ & $\begin{array}{c}\text { Saline } \\
\text { Saline }\end{array}$ \\
\hline
\end{tabular}

Twenty-four hours after the last injection the animals in each group were subdivided into unstressed and stressed subgroups. Four hours after the scalding stress, both the unstressed and stressed subgroups were sacrificed simultaneously. The pituitary glands of each subgroup were pooled and extracted for ACTH.

The pituitary glands of the experimental animals were extracted for ACTH according to the method of Birmingham and co-workers (20). These extracts were subsequently assayed for ACTH by incubation with rat adrenal slices in vitro by a modification of the method of Saffran and Schally (21) previously described (18). The pituitary extracts of the appropriate control animals were each assayed against a standard ACTH preparation. The absolute potencies of these control extracts are expressed as concentration of ACTH per mg. anterior pituitary tissue, and are included in Tables I, II and III. The pituitary extracts of the appropriate control animals then were employed as "house" standards in each experiment and assigned arbitrary potencies of 100 per cent. The pituitary ACTH concentrations in the various experimental groups are expressed as per cents of their respective controls. These percentages represent an arithmetic conversion of the mean log potency ratios obtained and are presented in this form solely for purposes of clarity. The absolute potencies of the various experi-

TABLE I

Changes in pituitary adrenocorticotropic hormone (ACTH) concentration in intact rats following termination of chronic cortisone administration

\begin{tabular}{cccc}
\hline \hline $\begin{array}{c}\text { Days } \\
\text { after last } \\
\text { cortisone } \\
\text { injection }\end{array}$ & $\begin{array}{c}\text { Number } \\
\text { of rats }\end{array}$ & $\begin{array}{c}\text { Pituitary } \\
\text { ACTH as } \% \\
\text { control } \\
\text { level* }\end{array}$ & $\begin{array}{c}\text { Combined } \\
\text { adrenal } \\
\text { weight }\end{array}$ \\
\hline & & $100 \ddagger$ & $m g$. \\
Control & 9 & $41 \pm 98$ & $16 \pm 3$ \\
1 & 4 & $41 \pm 16 \pm 1$ \\
2 & 4 & $32 \pm 68$ & $16 \pm 1$ \\
4 & 4 & $28 \pm 58$ & $16 \pm 1$ \\
7 & 4 & $47 \pm 88$ & $16 \pm 4$ \\
10 & 4 & $58 \pm 118$ & $16 \pm 3$ \\
\hline
\end{tabular}

*Antilog $\bar{M} \pm 2.303 S_{\bar{m}}(\operatorname{antilog} \bar{M})$.

$\dagger$ Mean \pm standard error of the mean.

\# Absolute potency, $41 \mathrm{mU}$ ACTH per $\mathrm{mg}$.

\& $\mathrm{p} \leqq 0.01$.
TABLE II

Effects of concurrent ACTH administration upon piluilary $A C T H$ depletion caused by cortisone in adrenalectomized rats

\begin{tabular}{lcc}
\hline \multicolumn{1}{c}{ Group } & $\begin{array}{c}\text { Number } \\
\text { of rats }\end{array}$ & $\begin{array}{c}\text { Pituitary } \\
\text { ACTH as \% } \\
\text { control } \\
\text { level* }\end{array}$ \\
\hline Saline (control) & 10 & $\begin{array}{c}100 \dagger \\
\text { Cortisone }\end{array}$ \\
Cortisone plus ACTH & 7 & $62 \pm 7 \ddagger$ \\
\hline
\end{tabular}

*Antilog $\bar{M} \pm 2.303 S_{\bar{m}}$ (antilog $\bar{M}$ ).

$\dagger$ Absolute potency, $50 \mathrm{mU}$ ACTH per mg.

$\ddagger \mathrm{p} \leqq 0.01$.

mental groups can be derived by simple multiplication of these per cents by the absolute potencies of the appropriate control extracts. Comparisons of differences in ACTH potency were determined from the mean log potency ratios and their respective log standard errors $(\bar{M} \pm s \bar{M})$ and not upon the arithmetic percentages (anti$\log \bar{M} \pm 2.303 \mathrm{~s} \overline{\mathrm{M}}$ antilog $\bar{M}$ ) presented in the tables. The data are calculated in the form of concentration of ACTH per mg. anterior pituitary tissue. Total ACTH content of the individual pituitary glands or pools was also calculated; however, in no instance do the values for ACTH content deviate significantly from those presented for concentration. Individual pituitary glands in Experiment 2 were assayed once each and the pituitary pools in Experiments 1,3 and 4 were assayed two to four times each. Statistical evaluations were calculated according to the methods of Bliss (22) and Snedecor (23).

\section{RESULTS AND DISCUSSION}

Although pituitary ACTH depletion is known to occur after prolonged steroid administration (17, 18 ), no data are available concerning the duration of this depletion following cessation of the steroid therapy. A significant fall in pituitary ACTH concentration to 41 per cent of control occurs in cortisone-treated rats 24 hours after the last injection when compared to saline-injected controls (Table I). However, the maximal depletion to 28 per cent of control is not observed until 4 days following treatment. This possibly reflects a continuing effect of cortisone due to delayed release of the steroid from the sites of injection. Thereafter, pituitary ACTH concentration increases gradually with a significant increment above the 4 day value noted 10 days after treatment. However, the latter level is still significantly lower than the control value. Despite this repletion of pituitary ACTH, repair of adrenal atrophy has not 
TABLE III

Effects of exogenous $A C T H$ upon pituitary ACTH concentration after steroid withdrawal and stress in intact rats

\begin{tabular}{|c|c|c|c|c|c|c|c|}
\hline \multicolumn{3}{|c|}{ Group } & \multicolumn{2}{|r|}{ Before stress } & \multicolumn{2}{|c|}{ After stress } & \multirow[b]{2}{*}{$\begin{array}{c}\text { Combined } \\
\text { adrenal } \\
\text { weight } \S \|\end{array}$} \\
\hline No. & $\underset{1}{\text { Treatment }}$ & $\underset{2}{\text { Treatment }}$ & $\begin{array}{c}\text { No. of } \\
\text { rats }\end{array}$ & $\begin{array}{c}\text { Pituitary } \\
\text { ACTH as } \% \\
\text { control level*.† }\end{array}$ & $\begin{array}{l}\text { No. of } \\
\text { rats }\end{array}$ & $\begin{array}{c}\text { Pituitary } \\
\text { ACTH as \% } \\
\text { control level*. }\end{array}$ & \\
\hline \multicolumn{7}{|c|}{ Experiment 3} & $m g$. \\
\hline $\begin{array}{l}1 \\
2 \\
3\end{array}$ & $\begin{array}{l}\text { Uninjected } \\
\text { Cortisone } \\
\text { Cortisone } \\
\text { plus ACTH }\end{array}$ & $\begin{array}{l}\text { Uninjected } \\
\text { Saline } \\
\text { Saline }\end{array}$ & $\begin{array}{l}8 \\
3 \\
3\end{array}$ & $\begin{array}{c}100 \text { (control) } \\
39 \pm 8^{* *} \\
53 \pm 7^{* *}\end{array}$ & $\begin{array}{l}3 \\
3 \\
3\end{array}$ & $\begin{array}{l}34 \pm 10^{* *} \\
20 \pm 8^{* *} \\
18 \pm 3^{* *}\end{array}$ & $\begin{array}{l}25 \pm 1 \\
14 \pm 1 \\
17 \pm 1\end{array}$ \\
\hline $\begin{array}{l}4 \\
5\end{array}$ & $\begin{array}{l}\text { Cortisone } \\
\text { Cortisone } \\
\text { plus ACTH }\end{array}$ & $\begin{array}{l}\text { ACTH } \\
\text { ACTH }\end{array}$ & $\begin{array}{l}3 \\
3\end{array}$ & $\begin{array}{l}33 \pm 8^{* *} \\
29 \pm 4^{* *}\end{array}$ & $\begin{array}{l}4 \\
4\end{array}$ & $\begin{array}{l}22 \pm 3 \\
26 \pm 4\end{array}$ & $\begin{array}{l}18 \pm 1(10) \\
21 \pm 1(10)\end{array}$ \\
\hline \multicolumn{8}{|c|}{ Experiment 4} \\
\hline & $\begin{array}{l}\text { Cortisone } \\
\text { Cortisone } \\
\text { plus ACTH }\end{array}$ & $\begin{array}{l}\text { Saline } \\
\text { Saline }\end{array}$ & $\begin{array}{l}4 \\
4\end{array}$ & $\begin{array}{c}100 \text { (control) } \\
81 \pm 12\end{array}$ & $\begin{array}{l}5 \\
6\end{array}$ & $\begin{array}{l}40 \pm 6^{* *} \\
43 \pm 7^{* *}\end{array}$ & \\
\hline
\end{tabular}

*Antilog $\overline{\mathrm{M}} \pm 2.303 \mathrm{~S}_{\overline{\mathrm{m}}}(\operatorname{antilog} \overline{\mathrm{M}})$.

† Calculation of significance of effects of treatment on pituitary ACTH before stress based on comparison with unstressed, uninjected control group.

¥ Calculation of significance of pituitary ACTH depletion after stress based on comparisons with respective prestress groups.

$\S$ Mean \pm standard error.

Number of animals studied indicated in parentheses.

f Absolute potency, $63 \mathrm{mU}$ ACTH per mg.

** $\mathrm{p} \leqq 0.01$.

begun by the tenth day (Figure 1). These data are compatible with the hypothesis that ACTH release is negligible after cessation of cortisone treatment in the unstressed rat and that the ACTH synthesized during this period is stored rather than secreted. Prolonged adrenal atrophy after

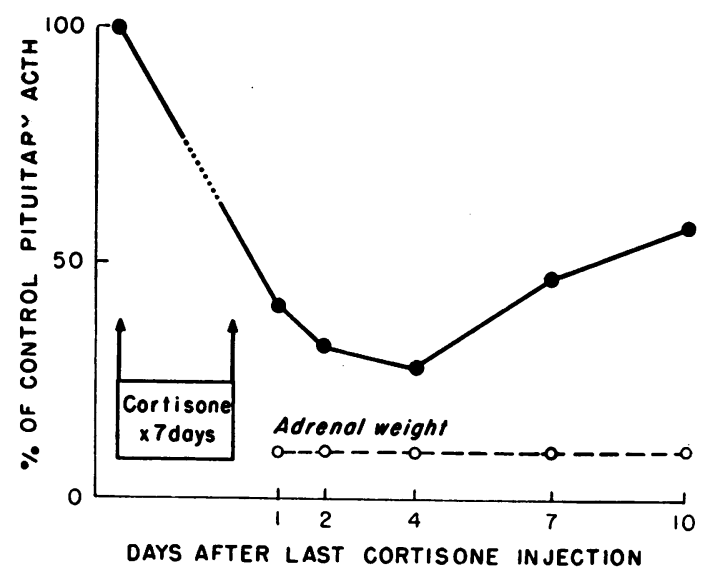

Fig. 1. Changes in Pituitary aCth Concentration and Adrenal Weight Following Cortisone AdMinistration for SEven Days

Graphic representation of data presented in Table I. Note persistent adrenal atrophy despite evidence of rising pituitary ACTH concentration 10 days following last cortisone injection. cortisone therapy has been observed previously in the rat (11) and also in man (7); in the latter report, adrenal atrophy (associated with sudden death following stress) was seen four and one-half months after completion of steroid treatment.

Since prolonged cortisone administration results in marked pituitary ACTH depletion, Experiments 2, 3 and 4 were designed to determine whether ACTH treatment can alter the pituitary ACTH content of cortisone-treated rats. A significant fall to 62 per cent of control occurs in adrenalectomized rats treated daily with $5 \mathrm{mg}$. cortisone alone compared to saline-injected controls (Table II). Concurrent administration of ACTH results in a significant fall to 74 per cent of the control level. The apparent difference of 12 per cent, although not significant, suggests that combined therapy may partially overcome the depletion of pituitary ACTH concentration induced by very large doses of cortisone.

Various schedules of combined ACTH and steroid therapy have been advocated for clinical use, e.g., administration of ACTH concurrently with steroids, ACTH following cessation of steroid treatment or ACTH both during and after steroid therapy. Consequently, these injection 


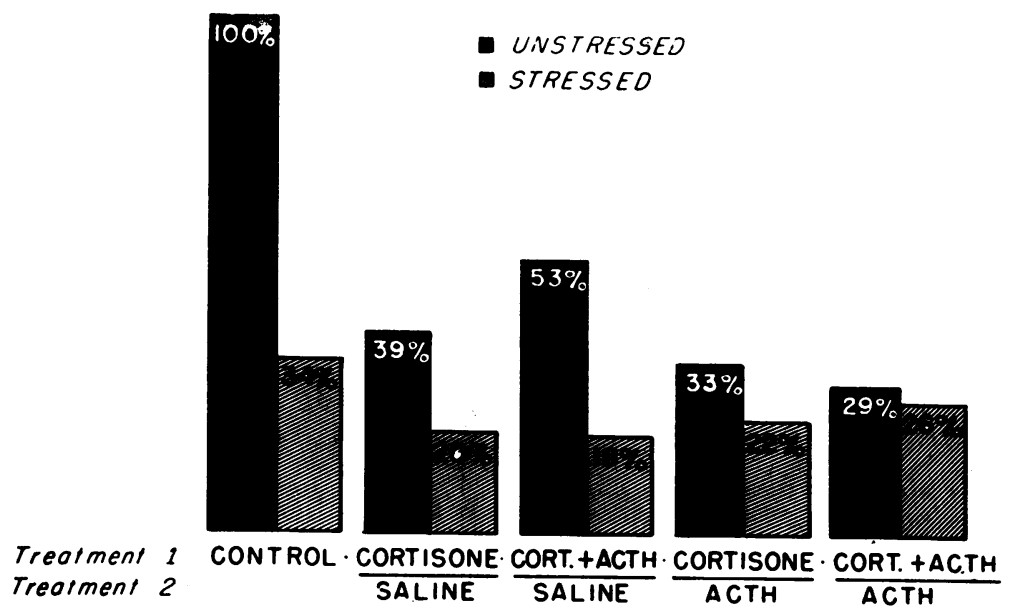

Fig. 2. Effects of ACTH Administration upon Pituitary aCTH Concentration in Cortisone-Treated Rats before and after Stress

Graphic representation of data presented in Table III. Pituitary ACTH concentrations are expressed as percentages of the control (uninjected) unstressed subgroup.

schedules were followed in Experiment 3 in addition to a group receiving cortisone without ACTH and an uninjected control group (Table III).

Animals treated with $2.5 \mathrm{mg}$. of cortisone without suplementary ACTH showed a depletion in pituitary ACTH concentration to 39 per cent of the control level four days after steroid withdrawal. This decrease is consistent with that seen in Experiment 1, in which twice the dose of cortisone caused a fall in pituitary ACTH to 28 per cent of the control level at a comparable interval following cessation of steroid administration.

No significant modification of this pituitary $\mathrm{ACTH}$ depletion is observed in any of the groups receiving exogenous $\mathrm{ACTH}$ in addition to steroids. As in Experiment 2, however, the animals injected with ACTH and cortisone concurrently (Group 3) demonstrate a pituitary ACTH concentration suggestively, but not significantly, greater than that obtained in animals given cortisone alone.

The hypothesis that exogenous ACTH is capable of improving the pituitary response of rats stressed after withdrawal of cortisone was tested by determining the effects of a scalding stress on pituitary ACTH concentration (Table III, Figure 2). Pituitary ACTH in uninjected rats after scalding is 34 per cent of the control level, repre- senting a fall of 66 per cent. On the other hand, the rats pretreated with cortisone (Group 2) show a poststress pituitary ACTH level of 20 per cent, in contrast to the pre-stress level of 39 per cent. This difference of 19 per cent, although statistically significant, is less than one-third that obtained in control animals. These findings suggest that $\mathrm{ACTH}$ release in response to stress is markedly reduced in rats during the period of steroid withdrawal.

It is assumed, in the above interpretation of the data, that the markedly smaller difference between pre- and poststress pituitary ACTH concentration in cortisone-treated rats primarily reflects diminished ACTH release. It is recognized that pituitary ACTH levels at any moment represent the algebraic sum of the synthesis and the release of ACTH. Negative ACTH balance, i.e., a decrease in pituitary ACTH level, may reflect reduced synthesis, accelerated release, or both conditions occurring concurrently. Positive ACTH balance, i.e., an increase in pituitary ACTH level, may represent accelerated synthesis, reduced or blocked release, or a combination of the two. When no change in ACTH balance is observed after an experimental procedure, no conclusion can be drawn as to the rates of synthesis and release, other than that the two processes are in equilibrium. In Experiment 3 (Table III, Fig- 
ure 2), the fall in pituitary ACTH following stress is over three times as great in the control animals (Group 1) as in the cortisone-treated rats (Group 2 ). If one proposes that equal quantities of $\mathrm{ACTH}$ were released by the two groups, then a rate of synthesis three times normal must be assumed for the group pretreated with cortisone. This last assumption appears untenable, in view of the data presented in Experiment 1 in which treatment with cortisone resulted in a severe depression of pituitary ACTH synthesis, as manifested by a striking and persistent decrease in pituitary ACTH content and adrenal weight. Therefore, a more appropriate explanation appears to be that the threefold difference in negative ACTH balance between Groups 1 and 2 after stress represents primarily a difference in the amounts of ACTH released by the two groups. The only assumption underlying this interpretation is that ACTH synthesis in the two groups is equivalent; the data of Experiment 1 indicate that this assumption is quite conservative. These considerations also apply to the discussion of the data which follow.

The rats pretreated with ACTH concurrently with cortisone (Group 3) also demonstrate a significant further reduction in pituitary ACTH as a result of stress. However, the change observed does not differ significantly from that obtained in rats given cortisone alone (Group 2), and is similarly much reduced in comparison to that observed in control animals. In contrast to the foregoing groups, rats injected with ACTH consecutively (Group 4) or concurrently plus consecutively (Group 5) do not exhibit significant falls in pituitary ACTH after the scalding stress. These data would suggest that ACTH therapy, when continued to the time of stress as in these last two groups, actually inhibits the release of ACTH from the pituitary gland. The findings are consistent with previous experiments (19) which demonstrated that administration of exogenous ACTH prevented release of endogenous ACTH in response to stress, via an extra-adrenal mechanism.

Definite adrenal atrophy persists following withdrawal of cortisone (Table III, Figure 3). All of the groups receiving ACTH in addition to the cortisone show significant increments in adrenal weights, as would be expected. The most effective maintenance of adrenal weight is seen in those animals receiving ACTH both during and following cortisone treatment (Group 5). When the mean adrenal weights are adjusted for variations in body weight by analysis of covariance, this group actually shows hypertrophy of the adrenals when compared to controls. ${ }^{1}$ However, this group manifested the most significant inhibition of pituitary ACTH release in response to stress (vide supra).

Since the data suggest that concurrent administration of ACTH to the cortisone-treated animal increases pituitary ACTH concentration following steroid withdrawal, a more precise experimental design was employed (Experiment 4), which involved a direct comparison of pituitary $\mathrm{ACTH}$ in the group receiving combined therapy to the group receiving cortisone alone, the latter

${ }^{1}$ Adjustment of mean adrenal weights for variations in body weight does not otherwise alter the significant differences depicted in Figure 3.

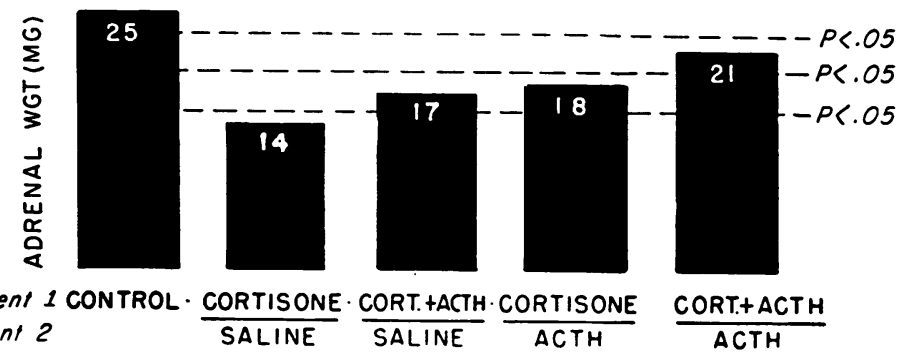

Fig. 3. Effects of ACTH Administration upon Adrenal Weight in Cortisone-Treated Rats

Means of the combined adrenal weights in the control and treatment groups of Experiment 3. Standard errors of these means are presented in Table III. Dotted lines indicate significant differences (at the 5 per cent level of confidence) among the various mean adrenal weights. 
serving as control (Table III). No significant difference between the pituitary ACTH concentrations of the two groups is seen, however, and the depletions in pituitary ACTH following stress are significant and similar in both groups when each is compared to its unstressed control.

It would appear then that in the rat receiving prolonged steroid therapy the administration of ACTH does not prevent or ameliorate the depletion of pituitary ACTH which results after cortisone. Nor is the diminished amount of ACTH released in response to severe stress increased by such therapy. The rat receiving ACTH up to 24 hours before stress shows the blockading effect of exogenous ACTH upon pituitary ACTH release in response to stress (19). However, administration of ACTH does prevent or repair adrenal atrophy in steroid-treated animals. In view of the inhibition of ACTH synthesis and release which has been demonstrated in animals receiving either cortisone alone, or combined treatment, the significance of this effect of $\mathrm{ACTH}$ is uncertain. It is possible that, with the ACTH-induced preservation of adrenal mass, the adrenal response to stress may be normal during the period of steroid withdrawal, despite the severe reduction in ACTH release. In the absence of data concerning adrenal steroid production under these conditions, no conclusions may be drawn concerning the adrenal response to stress. It should be emphasized that measurement of pituitary, and not adrenal, responsiveness to stress is the object of the present experiments.

The failure of exogenous ACTH to raise pituitary ACTH concentration in the steroid-treated rat in the above experiments is in striking contrast to the rise in pituitary ACTH seen following ACTH treatment in the normal or adrenalectomized rat $(18,19)$. The fall in pituitary ACTH after cortisone treatment is thought to represent inhibition of ACTH synthesis, and perhaps also inactivation of stored pituitary ACTH. Exogenous ACTH apparently is unable to reverse the steroid-induced inhibition of ACTH synthesis and depletion of ACTH stores.

Uncautious extrapolations from these studies to the clinical problems associated with steroid administration and withdrawal are not warranted. It is important to note that the dosages of hormones used in these experiments, calculated on the basis of body weight, represent amounts far in excess of those usually employed in the treatment of human disease. Moreover, important species differences may well exist between man and the rat insofar as pituitary-adrenal physiology is concerned.

However, clinical observations by Kyle, Meyer and Canary (24) in patients with Cushing's syndrome due to adrenal tumors correlate quite closely with the present animal studies. Adrenal insufficiency is frequently encountered following resection of such neoplasms. This has been attributed to the associated atrophy of the contralateral adrenal gland (25). Kyle's two patients, however, manifested persistent adrenal hypofunction for one to two years postoperatively after cessation of repeated courses of ACTH. Although ACTH was capable of stimulating the adrenals to produce normal levels of steroids, discontinuation of ACTH therapy was quickly followed by relapse into the hypoadrenal state. It was concluded, therefore, that the basic lesion in these patients was located in the pituitary gland rather than in the adrenals, since therapy directed at restoring adrenal weight was incapable in itself of returning adrenal function to normal.

On the other hand, Bondy and co-workers (26, 27) considered hypothalamic-pituitary-adrenal function to be normal in patients who had received prolonged ACTH and steroid therapy, despite the presence of "steroid withdrawal" symptoms. A conclusion of normal pituitary responsiveness was inferred from a rise in plasma corticoid level following the stress of hypoglycemia. The discrepancy between this conclusion and that obtained by direct measurements in rats in the present study perhaps may be explained by differences in the species and treatments employed. Final conclusions must await the development of techniques for the direct evaluation of pituitary $\mathrm{ACTH}$ reserve in man.

\section{SUMMARY}

1. Pituitary adrenocorticotropic hormone $(\mathrm{ACTH})$ concentration is significantly depleted following chronic administration of cortisone in the rat. Persistence of adrenal atrophy despite partial repletion of pituitary ACTH levels 10 days after cessation of treatment suggests that ACTH release during this period is negligible and that 
newly-synthesized ACTH is stored rather than secreted.

2. The steroid-induced depletion of pituitary ACTH concentration is neither prevented nor ameliorated by the addition of ACTH in a variety of dosage schedules. Adjunctive ACTH administration does not modify the striking reduction in $\mathrm{ACTH}$ release after stress which occurs in the cortisone-treated animal.

3. Adrenal atrophy following steroid treatment can be prevented or repaired by the administration of ACTH. The significance of this action of ACTH is uncertain, in view of the derangements in pituitary ACTH synthesis and release which are observed to exist in animals receiving either combined therapy or cortisone alone.

\section{ACKNOWLEDGMENTS}

We are indebted to Dr. C. J. O'Donovan of the Upjohn Company, Kalamazoo, Mich., for supplies of ACTH gel and cortisone acetate. Miss Myra Feder provided expert technical assistance.

\section{REFERENCES}

1. Forsham, P. H., Thorn, G. W., Frawley, T. F., and Wilson, L. W. Studies on the functional state of the adrenal cortex during and following ACTH and cortisone therapy (abstract). J. clin. Invest. 1950, 29, 812.

2. Sprague, R. G., Mason, H. L., and Power, M. H. Physiologic effects of cortisone and ACTH in man in Recent Progress in Hormone Research, G. Pincus, Ed. New York, Academic Press Inc., 1951, vol. 6, p. 315.

3. McIntosh, H. W., and Holmes, C. B. Some evidence suggesting the suppression of adrenocortical function by cortisone. Lancet 1951, 2, 1061.

4. Calkins, E., Bauer, W., Engel, L. L., and Carter, P. Metabolic and endocrinologic consequences of abrupt cessation of long-term cortisone therapy in rheumatoid arthritis (abstract). J. clin. Endocr. 1955, 15, 856.

5. Arlotti, O. Steroid withdrawal syndrome. Minerva med. (Torino) 1957, 48, 4143.

6. Fraser, C. G., Preuss, F. S., and Bigford, W. D. Adrenal atrophy and ireversible shock associated with cortisone therapy. J. Amer. med. Ass. 1952, 149, 1542.

7. Salassa, R. M., Bennett, W. A., Keating, F. R., Jr., and Sprague, R. G. Post-operative adrenal cortical insufficiency: Occurrence in patients previously treated with cortisone. J. Amer. med. Ass. 1953, 152, 1509.
8. Lewis, L., Robinson, R. F., Yee, J., Hacker, L. A., and Eisen, G. Fatal adrenal cortical insufficiency precipitated by surgery during prolonged continuous cortisone treatment. Ann. intern. Med. 1953, 39, 116.

9. Kittredge, W. E. Potential hazards of cortisone in treatment of prostatic cancer: Report of a fatal case. Trans. Amer. Ass. gen.-urin. Surg. 1954, 46, 57.

10. Ingle, D. J., and Kendall, E. C. Atrophy of the adrenal cortex of the rat produced by the administration of large amounts of cortin. Science 1937, 86, 245.

11. Winter, C. A., Silber, R. H., and Stoerk, H. C. Production of reversible hyperadrenocortinism in rats by prolonged administration of cortisone. Endocrinology 1950, 47, 60 .

12. Ingle, D. J. Effects of administering large amounts of cortin on the adrenal cortices of normal and hypophysectomized rats. Amer. J. Physiol. 1938, 124, 369.

13. Collins, E. J., and Olson, K. J. Inhibition of steroidinduced adrenal hypofunction. Proc. Soc. exp. Biol. (N. Y.) $1954,87,76$.

14. Young, I. I., De Filippis, V., Meyer, F. L., and Wolfson, W. Q. Maintenance of adrenal cortical responsiveness during prolonged corticoid therapy. Arch. intern. Med. 1957, 100, 1.

15. Vaccari, F., and Onesti, G. Use of long-acting adrenocorticotropic hormone (ACTH) for prevention of adrenal atrophy following treatment with cortisone and prednisone. Minerva med. (Torino) 1957, 48, 2959.

16. Vermeulen, A., and Vuylsteek, K. Iatrogenic adrenal insufficiency. Belg. T. Geneesk. 1957, 13, 1367.

17. Farrell, G. L., and Laqueur, G. Reduction of pituitary content of ACTH by cortisone. Endocrinology 1955, 56, 471.

18. Kitay, J. I., Holub, D. A., and Jailer, J. W. Hormonal regulation of pituitary adrenocorticotrophin. Proc. Soc. exp. Biol. (N. Y.) 1958, 97, 165.

19. Kitay, J. I., Holub, D. A., and Jailer, J. W. Inhibition of pituitary ACTH secretion: An extra-adrenal action of exogenous ACTH. Endocrinology. In press.

20. Birmingham, M. K., Kurlents, E., Rochefort, G. J., Saffran, M., and Schally, A. V. ACTH content of rat pituitary glands. Endocrinology 1956, 59, 677.

21. Saffran, M., and Schally, A. V. In vitro bioassay of corticotropin: Modification and statistical treatment. Endocrinology 1955, 56, 523.

22. Bliss, C. I. The Statistics of Bioassay. New York, Academic Press Inc., 1952.

23. Snedecor, G. W. Statistical Methods. Ames, The Iowa State College Press, 1956. 
24. Kyle, L. H., Meyer, R. J., and Canary, J. J. Mechanism of adrenal atrophy in Cushing's syndrome due to adrenal tumor. New Engl. J. Med. 1957, 257, 57.

25. Kepler, E. J. Diseases of the adrenal glands; review with special reference to clinical aspects. Arch. intern. Med. 1935, 56, 105.

26. Bondy, P. K., Hollingsworth, D., D'Esopo, N. D., and
Upton, G. V. Normal adrenal responsiveness in "withdrawal hypoadrenalism." Clin. Res. 1958, 6, 26.

27. Amatruda, T. T., Jr., Hollingsworth, D., D'Esopo, N., Upton, G. V., and Bondy, P. K. Evidence for integrity of hypothalamic-pituitary-adrenal system after steroid withdrawal. Clin. Res. 1958, 6, 253. 